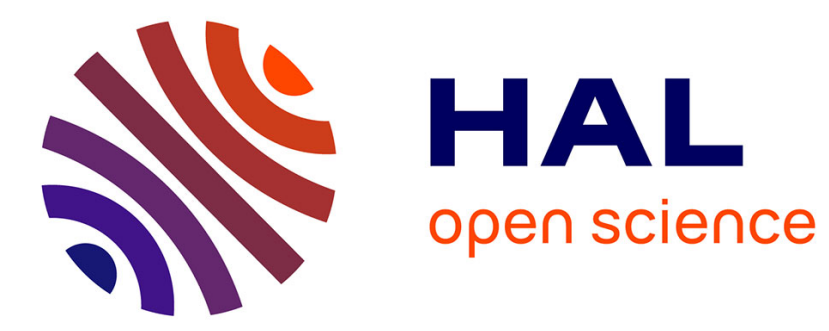

\title{
Electro-elastic moduli and frequency dependence of KN single crystal
}

R Rouffaud, F. Levassort, M. Pham-Thi, E. Leveugle, Anne-Christine Hladky

\section{To cite this version:}

R Rouffaud, F. Levassort, M. Pham-Thi, E. Leveugle, Anne-Christine Hladky. Electro-elastic moduli and frequency dependence of KN single crystal. 2012 Joint 21st IEEE ISAF / 11th IEEE ECAPD / IEEE PFM (ISAF/ECAPD/PFM), Jul 2012, Aveiro, Portugal. pp.1-4, 10.1109/ISAF.2012.6297785 . hal-01705153

\section{HAL Id: hal-01705153 \\ https://hal.science/hal-01705153}

Submitted on 22 Mar 2018

HAL is a multi-disciplinary open access archive for the deposit and dissemination of scientific research documents, whether they are published or not. The documents may come from teaching and research institutions in France or abroad, or from public or private research centers.
L'archive ouverte pluridisciplinaire HAL, est destinée au dépôt et à la diffusion de documents scientifiques de niveau recherche, publiés ou non, émanant des établissements d'enseignement et de recherche français ou étrangers, des laboratoires publics ou privés. 


\section{Electro-elastic Moduli and Frequency Dependence of KN Single Crystal}

\author{
R. Rouffaud, F. Levassort \\ GREMAN, CNRS UMR7347 \\ Université François-Rabelais de \\ Tours, France \\ e-mail : remi.rouffaud@univ-tours.fr
}

\author{
M. Pham-Thi, E. Leveugle \\ Thales Research and Technology \\ Palaiseau, France
}

\author{
A.-C. Hladky-Hennion \\ IEMN, CNRS UMR8520 \\ Lille, France
}

\begin{abstract}
Functional properties of $\mathbf{K N b O}_{3}$ single crystal are characterized. Large polydomain plates cutted from an as-grown $\mathrm{KNbO}_{3}$ crystal (oriented along $[001]_{c}\left(45^{\circ}\right.$-cut) direction) are used. At the fundamental resonance $(10 \mathrm{MHz})$, thickness coupling factor is $65 \%$ and frequency dependence is measured with overtone resonances. Its variation is relatively high and reduces to around $45 \%$ at $160 \mathrm{MHz}$. Electro-elastic moduli are also determined by mixing measured parameters (from thickness and lateral modes) and constants already published as initial data. Final constants are obtained by a minimization process to tend toward a self-consistent electro-elastic moduli which is an important condition for numerical modelling.
\end{abstract}

\section{Single crystal, lead-free, functional characterization}

\section{INTRODUCTION}

Nowadays, thanks to the use of dopants/additives and efficient production processes, PZT-based compositions are the dominant piezoceramics since their electroacoustic properties are high. This increasing success of PZT can be associated to health and environmental problems because PZT contains lead. Due to their increasing use, more and more lead is released. As a consequence, several countries over the word have included PZTs in their legislation as hazardous substances to be substituted by safer materials [1]. Their objective is to protect human health and environment by substituting hazardous chemicals by safer ones. Lead-free potassium niobate $\left(\mathrm{KNbO}_{3}\right)$ single crystal can be a candidate to replace PZT. It can deliver high electromechanical performance with a maximum thickness coupling factor $\mathrm{k}_{\mathrm{t}}$ of $69 \%$ for specific cuts and orientations [2-5]. This value combined with a low density and high acoustic velocity compared to those of lead-based compositions makes it an interesting and efficient material for various applications in particular for their integration in ultrasonic transducers for medical imaging or non-destructive evaluation. However, in order to use this $\mathrm{KNbO}_{3}$ material in devices, preliminary steps of design and modelling are often necessary, and for this all constants of the electro-elastic tensor are required, in particular when numerical models such as the finite element method are used.

In this work, two main studies are performed on as-grown $\mathrm{KNbO}_{3}$ crystal plate (oriented along $[001]_{\mathrm{c}}\left(45^{\circ}\right.$-cut) direction). The first one is a functional characterization of the thickness mode on the fundamental resonance and its overtones. By this way, a frequency dependence up to $150 \mathrm{MHz}$ is deduced. The second study is the determination of the electro-elastic moduli obtained by mixing data from our measurements and a previously published database [6]. This step is performed in order to minimize the inconsistencies between the different constants of the material tensors.

\section{EXPERIMENTAL PROCEDURE}

In this study a set of large unpoled polydomain plates $(10 \times 10 \times 0.4 \mathrm{~mm})$ are cut from an as-grown $\mathrm{KNbO}_{3}$ crystal (from FEE GmbH [7], oriented along [001] $]_{\mathrm{c}}\left(45^{\circ}\right.$-cut) direction). At room temperature, $\mathrm{KNbO}_{3}$ belongs to the point group $2 \mathrm{~mm}$ of the orthorhombic system [8] and one representative plate is used for this analysis.

\section{A. KLM model (for thickness mode)}

The KLM model [9] is used to characterize the electromechanical properties of the thickness mode of 7 samples. Mechanical and dielectric losses are introduced [10] and this equivalent electrical circuit model allows to calculate the complex electrical impedance as a function of frequency. In this model, the sample properties involved are : the density $(\rho)$, the thickness $(t)$, the longitudinal wave velocity $\left(v_{1}\right)$, the dielectric constant at constant strain $\left(\varepsilon_{33}{ }^{S}\right)$, the thickness coupling factor $\left(\mathrm{k}_{\mathrm{t}}\right)$, dielectric $\left(\delta_{\mathrm{e}}\right)$ and mechanical $\left(\delta_{\mathrm{m}}\right)$ losses. The experimental set-up used to measure this electrical impedance is composed of an HP4395A spectrum analyzer with its impedance test kit and specific spring clip fixture. The theoretical data is fitted to the experimental curves of the electrical impedance in keeping as variables: $\mathrm{v}_{\mathrm{l}}, \varepsilon_{33} \mathrm{~S}, \mathrm{k}_{\mathrm{t}}, \delta_{\mathrm{e}}$ and $\delta_{\mathrm{m}}$. Density (Archimede's method) and thickness are previously measured.

Parameters of lateral mode $\left(\mathrm{v}_{\mathrm{l}}, \mathrm{k}_{31}\right.$ and $\left.\varepsilon_{33}{ }^{\mathrm{T}}\right)$ are also deduced with the IEEE standard $[11,12]$ from the resonance and anti-resonance frequencies, dimensions and capacitance at twice anti-resonance frequency.

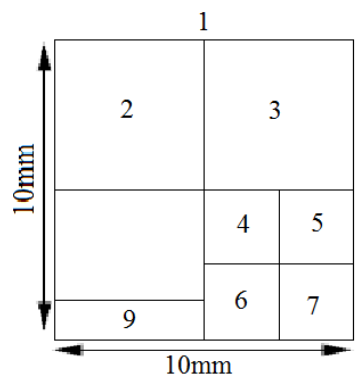

Figure 1 : Schematic drawing (top view) of $\mathrm{KN}$ single crystal used, corresponding cuts and sample numbers. 


\section{B. Measurements}

The characterization procedure described in the previous paragraph for the thickness mode is applied on each overtone in order to determine the parameters at the corresponding resonance frequency. Consequently, behavior as a function of frequency can be determined. For each sample, 7 or 8 fits are made (from the fundamental resonance until the $6^{\text {th }}$ or $7^{\text {th }}$ overtone) for a frequency range between 10 and $160 \mathrm{MHz}$.

The thickness of the samples is $395 \pm 2 \mu \mathrm{m}$ and gold electrodes are sputtered on both faces ( $400 \mathrm{~nm}$ thick). Area of each sample is given in Table I. Measured density is $4575 \pm 40$ $\mathrm{kg} / \mathrm{m}^{3}$.

All these samples are obtained from one originally piece (the sample numbered 1) to quantify the homogeneity of the properties (Figure 1). First, the square sample 1 is cut in four equal new samples and measurements with samples 2 and 3 are performed. Finally, one of these four samples is divided in new four smaller squares (samples 4 to 7 ).

A last sample is fabricated (numbered 9, Figure 1) to measure lateral mode parameters. The dimensions are $0.86 \times 5.09 \times 0.393 \mathrm{~mm}$.

\section{RESULTS AND DISCUSSION}

\section{A. Functional characterization (thickness mode)}

As mentioned before, values of several parameters are measured in using the overtones and only for the thickness mode. Figure 2 shows the fitted experimental impedances with KLM model around the fundamental resonance, the $3^{\text {rd }}$ and $15^{\text {th }}$ overtones for the sample 4 . As for all samples, at the fundamental resonance (around $10 \mathrm{MHz}$ ), few inaccuracies are observed due to perturbation (Fig 2(a)). This leads, with the fitting process, to an overestimated mechanical losses but also small errors for the resonance and anti-resonance frequencies and consequently longitudinal wave velocity and coupling factor. The functional characterization with the $3^{\text {rd }}$ overtone (around $30 \mathrm{MHz}$ ), allows to determine with a good accuracy the properties (as shown on Fig 2(b)). Finally, measurements until $160 \mathrm{MHz}$ (in using the $15^{\text {th }}$ overtone) are performed (Fig 2(c). At high frequencies, additional resonances can appear but parameters are extracted with good accuracy. We can also notice that for these frequencies, the electrodes (and in particular their thicknesses) can have a non negligible influence on final parameters. Typically, variations of the longitudinal wave velocity is $50 \mathrm{~m} / \mathrm{s}$ and the thickness coupling factor of $2.5 \%$ (at $150 \mathrm{MHz}$ ). For all the characterizations, the gold electrodes were taken into account. Table I summarizes the electromechanical properties for the seven samples deduced from the $3^{\text {rd }}$ overtone. The corresponding resonance frequencies for the seven samples are between 30 and $30.6 \mathrm{MHz}$. Non negligible variations properties are observed between samples. The lowest values $\left(\mathrm{k}_{\mathrm{t}}\right)$ are measured from the original sample 1 with the highest area. In decreasing the area, this coupling factor increases (samples 2 and 3) and for the smallest area (samples 4 to 7), reproducible results are observed with a $\mathrm{k}_{\mathrm{t}}$ around $61 \%$ and dielectric constant (at constant strain) around 33.
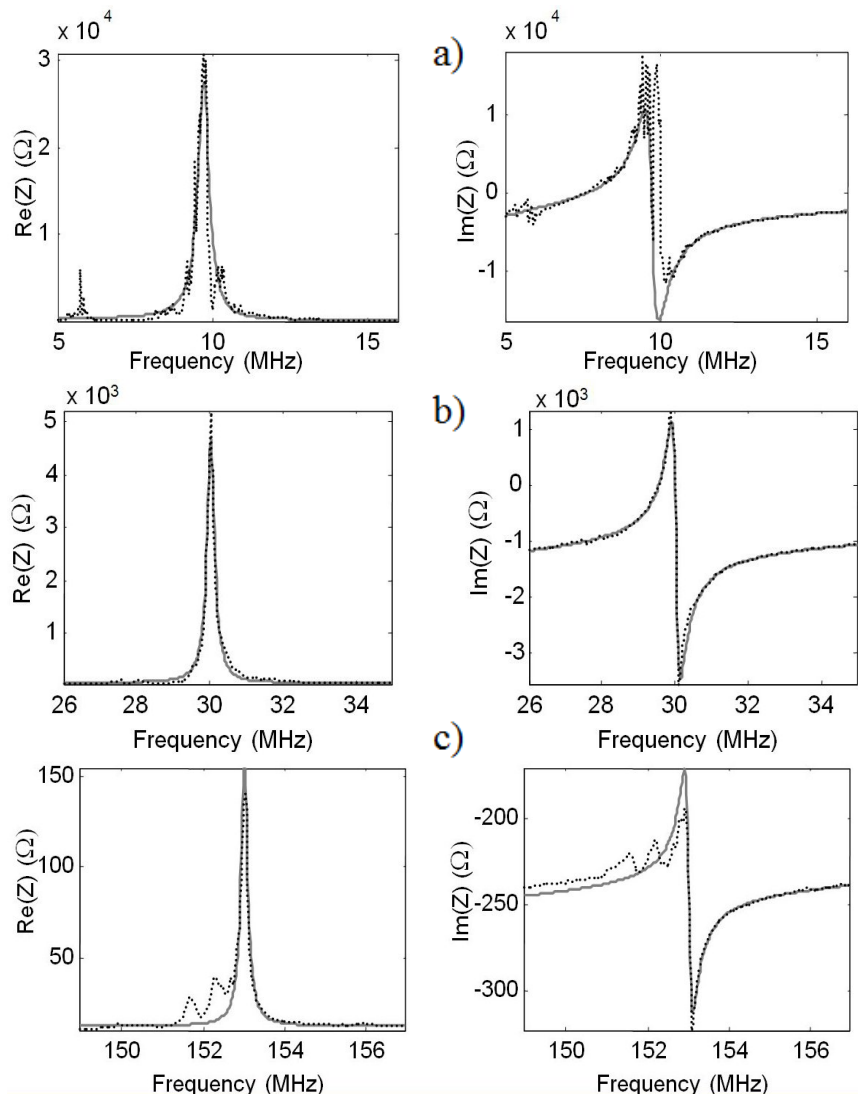

Figure 2 : experimental (black points) and theoretical (grey solid lines) complex electrical impedances at (a) fundamental resonance, (b) 3rd overtone, (c) 15 th overtone.

These values can be compared with those given in $[3,4]$. For the two references, thickness coupling factors are higher than those we measured (typically between 61 and $70 \%$ ) even for the fundamental resonance where the $\mathrm{k}_{\mathrm{t}}$ is around $65 \%$. Here our polydomain samples were not poled before our measurements but it seems that this poling step has a relatively low influence on final coupling factor $[4,5]$. Figures 3,4 and 5 represent the behavior of thickness coupling factor, dielectric constant (at constant strain) and piezoelectric coefficient respectively for each overtone (until $15^{\text {th }}$ overtone) and consequently as a function of frequency.

TABLE I. DIMENSIONS AND ELECTROMECHANICAL PROPERTIES (THICKNESS MODE) OF SAMPLES MEASURED AT THE 3RD OVERTONE (30 MHZ)

\begin{tabular}{|c|c|c|c|c|c|}
\hline \multirow{2}{*}{$\begin{array}{l}\text { Sample } \\
\text { number }\end{array}$} & \multicolumn{5}{|c|}{ Electromechanical properties ${ }^{a}$} \\
\hline & $A(m m)^{2}$ & $k_{t}(\%)$ & $\varepsilon_{33} s / \varepsilon_{0}$ & $V_{l}(m / s)$ & $\delta_{m}(\%)$ \\
\hline 1 & 100.6 & 49 & 29 & 8040 & 0.4 \\
\hline 2 & 24.5 & 57.7 & 32 & 7965 & 1.9 \\
\hline 3 & 25.4 & 62.8 & 30 & 7995 & 0.9 \\
\hline 4 & 6.3 & 61.6 & 33 & 7980 & 1.3 \\
\hline 5 & 6.0 & 60.7 & 35 & 7960 & 1.6 \\
\hline 6 & 6.1 & 60.9 & 33 & 7900 & 1.3 \\
\hline 7 & 6.4 & 61.6 & 33 & 7950 & 1.5 \\
\hline
\end{tabular}




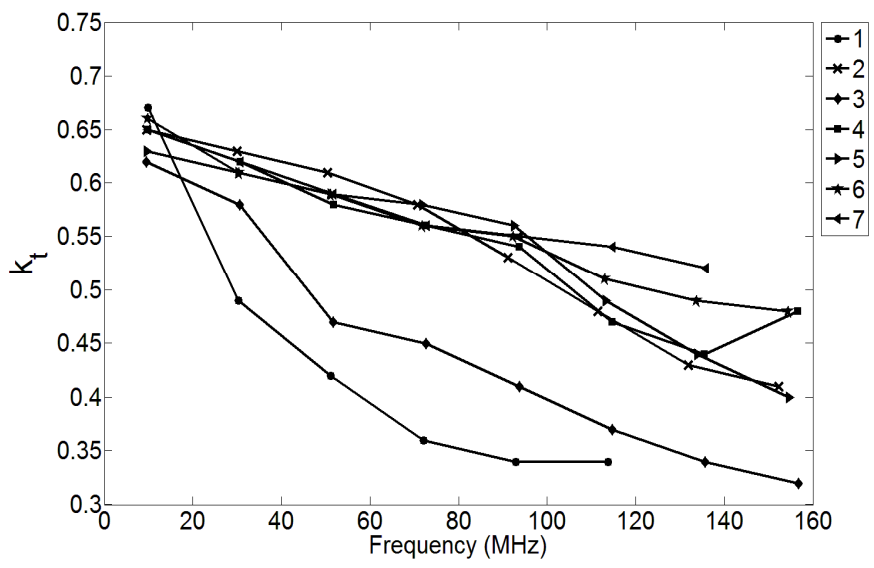

Figure 3 : piezoelectric coefficient $\left(\mathrm{k}_{\mathrm{t}}\right)$ as a function of frequency deduced from overtones (for samples 1 to 7 ).

Significant variations are observed on Figure 3. The decrease of $\mathrm{k}_{\mathrm{t}}$ value for the largest sample 1 is the most important and this variation is lower for the four smallest samples (4 to 7). In any cases, this variation is important (from around $65 \%$ at $10 \mathrm{MHz}$ to $45 \%$ at $160 \mathrm{MHz}$ ) on contrary to a similar study performed for PZN-PT single crystals where a good stability is measured [13]. For the dielectric constant at constant strain, the dependence frequency is low (Figure 4).

Finally in Figure 5, piezoelectric coefficient $\left(\mathrm{e}_{33}\right)$ has a large frequency dependence (over 30\%). In meantime, the longitudinal wave velocity tends to slightly increase with higher overtones (and consequently elastic constant $\mathrm{c}_{33}{ }^{\mathrm{E}}$ ). To conclude, the decrease of the thickness coupling factor is mainly due to the decrease of the piezoelectric coefficient $\left(\mathrm{k}_{\mathrm{t}}{ }^{2}=\mathrm{e}_{33}{ }^{2} /\left(\mathrm{c}_{33}{ }^{\mathrm{D}} \varepsilon_{33}{ }^{\mathrm{S}}\right)\right)$. In all these characterizations, dielectric and mechanical losses are very low. The dielectric constant was quasi-stable with a value at $0.5 \%$. For the mechanical losses, small variations are observed. As explained before, the highest $\left(\delta_{\mathrm{m}}\right)$ value is measured at the resonance frequency (typically 4-6\%), and for the overtones, these values are quasi constant (between $0.7 \%$ and $0.15 \%$ ).

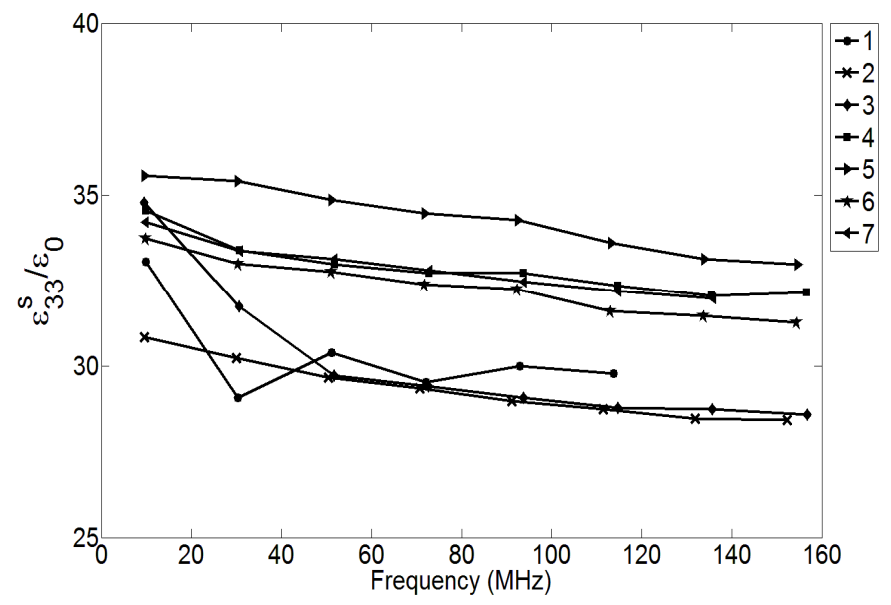

Figure 4 : Dielectric constant at constant strain $\left(\varepsilon_{33} \mathrm{~s} / \varepsilon_{0}\right)$ as a function of frequency deduced from overtones (for samples 1 to 7 ).

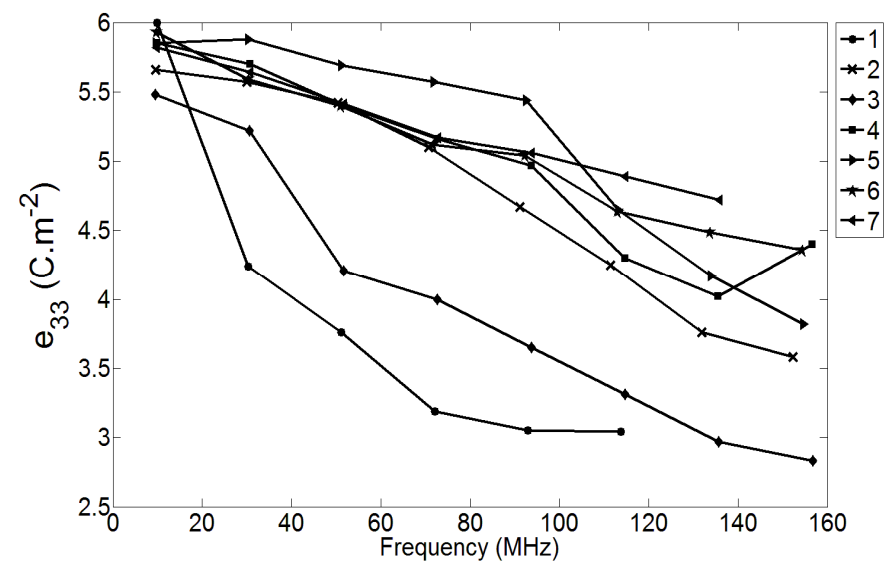

Figure 5 : piezoelectric coefficient $\left(\mathrm{e}_{33}\right)$ as a function of frequency deduced from overtones (for samples 1 to 7 ).

\section{B. Electro-elastic moduli determination}

According to previous results deduced from the thickness and lateral modes, several parameters are definitively measured: $\mathrm{s}_{11}{ }^{\mathrm{E}}, \varepsilon_{33}{ }^{\mathrm{T}}, \mathrm{d}_{31}, \mathrm{~s}_{11}{ }^{\mathrm{D}}, \mathrm{c}_{33}{ }^{\mathrm{D}}, \varepsilon_{33}{ }^{\mathrm{S}}, \mathrm{e}_{33}$ and $\mathrm{c}_{33}{ }^{\mathrm{E}}$.

To determine experimentally the complete elastic, piezoelectric and dielectric constants, several authors combined successfully resonance and ultrasonic methods [14]. Then, the obtained electro-elastic moduli must satisfy several criteria to avoid violations of the interrelations between particular groups of electromechanical constants and keep the thermodynamic stability [15]. These conditions are of primary interest for numerical modelling of transducers in particular in using finite element method where the self-consistency of all these parameters avoid errors in the calculation. Here, we propose a simple method by combining our measured parameters and a previous published database [6] to tend toward a consistent electro-elastic moduli of the KN single crystal under study. For that, the five following matrix relations must be verified [12]: $c^{E}=\left(s^{E}\right)^{-1}$,

$\mathrm{e}=\mathrm{dc}^{\mathrm{E}}$,

$\varepsilon^{\mathrm{S}}=\varepsilon^{\mathrm{T}}-\mathrm{d}\left(\mathrm{c}^{\mathrm{E}}\right) \mathrm{d}^{\mathrm{t}}$,

$\mathrm{s}^{\mathrm{D}}=\mathrm{s}^{\mathrm{E}}-\mathrm{d}^{\mathrm{t}}\left(\varepsilon^{\mathrm{T}}\right)^{-1} \mathrm{~d}$,

and $c^{D}=c^{E}+e^{t}\left(\varepsilon^{S}\right)^{-1} e$.

The aim of the procedure is to respect as much as possible all of these five last relations without giving more importance to one or the other. As a consequence, none of these matrix relations is purely checked. For that, a simple minimization function $\alpha$ is defined integrating all the constants. The values of these constants are previously normalized to deliver the same weight for all the constants. It is defined as the sum of differences between all the constants of each tensor.

For (1), it can be written that

$$
\boldsymbol{\alpha}_{1}=\left[c_{11}^{E}-\left(s^{E}\right)_{11}^{-1}\right]+\left[c_{12}^{E}-\left(s^{E}\right)_{12}^{-1}\right]+\ldots+\left[c_{66}^{E}-\left(s^{E}\right)_{66}^{-1}\right] \text {, }
$$

and in same way for (2) :

$$
\boldsymbol{\alpha}_{2}=\left[e_{11}-\left(d c^{E}\right)_{11}\right]+\left[e_{12}-\left(d c^{E}\right)_{12}\right]+\ldots+\left[e_{66}-\left(d c^{E}\right)_{66}\right] \text {. }
$$

Finally, the constant $\alpha$ is deduced from all matrix equations :

$$
\alpha=\alpha_{1}+\alpha_{2}+\alpha_{3}+\alpha_{4}+\alpha_{5} \text {. }
$$


TABLE II. MEASURED AND DERIVED MATERIAL PROPERTIES OF KN SINGLE CRYSTAL ${ }^{\mathrm{a}}$

\begin{tabular}{|c|c|c|c|c|c|c|c|c|c|c|c|c|c|c|c|c|c|}
\hline & $\overline{[\mathrm{IGPa}]}$ & $\%$ & & {$[\overline{[p m / N]}$} & $\%$ & & $\overline{[\mathrm{C}} \mathrm{GPa}]$ & $\overline{0 \%}$ & & {$[\mathrm{pm} / \mathrm{N}]$} & $\overline{0 \%}$ & & $\overline{[e}[p C / N]$ & $\overline{0 \%}$ & & {$\left[\mathrm{C} / \mathrm{m}^{2}\right]$} & $\%$ \\
\hline$c_{11}^{E}$ & 225.1 & 0.4 & $s_{11}^{E}$ & 5.05 & $\mathbf{0}$ & $c_{11}^{D}$ & 235.6 & 8.2 & $s_{11}^{D}$ & 4.76 & 0 & $d_{31}$ & 16.36 & $\mathbf{0}$ & $e_{31}$ & 2.43 & 1.2 \\
\hline$c_{12}^{E}$ & 97.6 & 1.6 & $s_{12}^{E}$ & -1.24 & 19 & $c_{12}^{D}$ & 82.9 & 0.1 & $s_{12}^{D}$ & -0.95 & 7 & $d_{32}$ & -16.58 & 18 & $e_{32}$ & -0.93 & 18 \\
\hline$c_{13}^{E}$ & 69.7 & 2.4 & $s_{13}^{E}$ & -1.05 & 11 & $c_{13}^{D}$ & 119.8 & 0.2 & $s_{13}^{D}$ & -1.5 & 29 & $d_{33}$ & 29.14 & 0.5 & $e_{33}$ & 5.69 & 0 \\
\hline$c_{22}^{E}$ & 254.1 & 6.3 & $s_{22}^{E}$ & 5.08 & 0.4 & $c_{22}^{D}$ & 275.3 & 0.2 & $s_{22}^{D}$ & 4.7 & 12 & $d_{24}$ & 85.85 & 9.1 & $e_{24}$ & 11.73 & 0.2 \\
\hline$c_{23}^{E}$ & 102 & 1 & $s_{23}^{E}$ & -1.98 & 11 & $c_{23}^{D}$ & 81.1 & 5.1 & $s_{23}^{D}$ & -1.44 & 52 & $d_{15}$ & 104.6 & 1.5 & $e_{15}$ & 5.16 & 0 \\
\hline$c_{33}^{E}$ & 178.4 & $\mathbf{0}$ & $s_{33}^{E}$ & 7.62 & 8.2 & $c_{33}^{D}$ & 288 & 0 & $s_{33}^{D}$ & 6.51 & 29 & - & - & $\%$ & - & - & $\%$ \\
\hline$c_{44}^{E}$ & 76.1 & 2.4 & $s_{44}^{E}$ & 13.51 & 0.4 & $c_{44}^{D}$ & 94.6 & 0.6 & $s_{44}^{D}$ & 12.88 & 17 & $\varepsilon_{11}^{\mathrm{T}}$ & 131 & 15 & $\varepsilon_{11}^{\mathrm{S}}$ & 35 & 5 \\
\hline$c_{55}^{E}$ & 27.3 & 8.4 & $s_{55}^{E}$ & 36.17 & 11 & $c_{55}^{D}$ & 113 & 0.4 & $S_{55}^{D}$ & 31.93 & 72 & $\varepsilon_{22}{ }^{\mathrm{T}}$ & 844 & 17 & $\varepsilon_{22}^{\mathrm{S}}$ & 888 & 12 \\
\hline$c_{66}^{E}$ & 93.7 & 1.9 & $s_{66}^{E}$ & 10.67 & 1.9 & $c_{66}^{D}$ & 94.8 & 0.7 & $s_{66}^{D}$ & 10.39 & 0.8 & $\varepsilon_{33}{ }^{\mathrm{T}}$ & 103 & $\mathbf{0}$ & $\varepsilon_{33}^{\mathrm{s}}$ & 33 & 0 \\
\hline
\end{tabular}

In the case of perfect self-consistent electro-elastic moduli, the $\alpha$ function is zero. Values from M. Zgonik et al. [7] are used as the initial database of complete set (except those we determined from sample 4 with the $3^{\text {rd }}$ overtone). For this first step, the corresponding $\alpha$ value is different from zero (here 2503). After the minimization step, the "optimized" constants are summarized in Table II and the corresponding $\alpha$ value is $6.90 .10^{-7}$. In Table II, the relative differences between initial values from [7] and optimized values are given for each constant. In accordance with fixed parameters before the procedure, the corresponding difference is zero.

\section{CONCLUSION}

Large polydomain plates from an as-grown $\mathrm{KNbO}_{3}$ crystal (oriented along $[001]_{\mathrm{c}}-45^{\circ}$-cut direction) were studied at room temperature. Functional parameters of the thickness mode were measured from $10 \mathrm{MHz}$ to $160 \mathrm{MHz}$ by using the overtone resonances (from the 3rd to 15th overtones). The frequency dependence and inhomogeneity of the thickness coupling factor are higher than those published for PZN-PT single crystal [13]. This frequency behavior must be confirmed by lapping samples at several lower thicknesses and then measuring the properties at the fundamental thickness resonance. In [4], a thin sample (60 $\mu$ m thick) was shown to have similar properties, (in particular $k_{t}$ ) to those of a thicker sample. Electro-elastic moduli was determined with measured parameters and a simple minimization process in order to tend towards selfconsistent moduli. This database is useful for numerical modelling. To improve the accuracy of these tensors, additional constants must be measured through several resonances modes such as length- extensional modes $\left(\mathrm{k}_{33}\right)$.

\section{ACKNOWLEDGMENT}

Authors thank Claire Bantignies from VERMON SA (Tours, France) for the cuts of the samples. This work was funded by the French Research Agency (ANR HYPERCAMPUS Mat\&Pro) and European Union (FEDER Funds).

\section{REFERENCES}

[1] J. Rödel, W. Jo, K.T.P. Seifert, E.-M. Anton, T. Granzow, D. Damjanovic "Perspective on the development of lead-free piezoceramics", J. Am. Ceram Soc., Vol. 92(6), pp. 1153-11177, 2009.

[2] K. Nakamura and Y. Kawamura, "Orientation Dependence of Electromechanical Coupling Factors in $\mathrm{KNbO}_{3}$ ", IEEE Trans. Ultrason., Ferroelect., Freq. Contr., vol. 47(3), pp. 750-755, 2000.

[3] K. Nakamura, T. Tokiwa, Y. Kawamura, "Domain structures in $\mathrm{KNbO}_{3}$ crystals and their piezoelectric properties", J. App. Phys., vol. 91, 9272, 2002.

[4] M. Davis, N. Klein, D. Damjanovic, N. Setter, "Large and stable thickness coupling coefficients of $[100] \mathrm{c}$-oriented $\mathrm{KNbO} 3$ and $\mathrm{Li}$ modified $(\mathrm{K}, \mathrm{Na}) \mathrm{NbO} 3$ single crystal”, App. Phys. Lett., vol. 90, 062904, 2007.

[5] N. Klein, "Properties and phase transitions in lead free piezoelectrics : $(\mathrm{K}, \mathrm{Na}) \mathrm{NbO}_{3}-\mathrm{LiNbO}_{3}$ and $(\mathrm{Bi}, \mathrm{Na}) \mathrm{TiO}_{3}-\mathrm{BaTiO}_{3}{ }^{\prime \prime}, \mathrm{PhD}$ Thesis, Ecole Polytechnique Fédérale de Lausanne, 2009.

[6] M. Zgonik, R. Schlesser, I. Biaggio, E. Voit, J. Tscherry and P. Günter, "Materials constants of $\mathrm{KNbO}_{3}$ relevant for electro- and acousto-optics", J. of App. Phys., vol. 74, 1287, 1993.

[7] http://www.fee-io.de/

[8] J. Hirohashi, K. Yamada, H.Kamio, M. Uchida and S. Shichijyo, "Control of specific domain structure in $\mathrm{KNbO}_{3}$ single crystals by differential vector poling method", J. App. Phys., vol. 98, 2005.

[9] R. Krimholtz, D.A. Leedom and G.L. Mathei, "New equivalent circuit for elementary piezoelectric transducers", Electron. Lett., vol. 38, pp. 398-399, 1970.

[10] M. Lethiecq , L.P. Tran Huu Hue, F. Patat, L. Pourcelot, "Measurement of losses in five piezoelectric ceramics between 2 and $50 \mathrm{MHz}$, IEEE Trans. Ferro. Freq. Control, vol. 43(3), pp. 232-237, 1993.

[11] "ANSI/IEEE Standard on Piezoelectricity", IEEE Trans. Ultrason., Ferroelect., Freq. Contr., vol. 43, pp. 719-722, 1996

[12] M. Brissaud, "Matériaux piézoélectriques : caractérisation, modélisation et vibration", 1st ed., Presses Polytechniques et Universitaires Romandes, Lausanne, 2007.

[13] T. Delaunay, "Caractérisation fonctionnelle et relations structure propriétés de monocristaux piézoélectriques de type pérovskite”, $\mathrm{PhD}$ Thesis (in French), François-Rabelais University, Tours, France, 2006.

[14] H. Cao, V.H. Schmidt, R. Zhang, W. Cao, H. Luo, "Elastic, piezoelectric, and dielectric properties of $0.58 \mathrm{~Pb}\left(\mathrm{Mg}_{1 / 3} \mathrm{Nb}_{2 / 3}\right) \mathrm{O}_{3^{-}}$ 0.42 $\mathrm{PbTiO}_{3}$ single crystal", J. Appl. Phys., vol. 96, 549, 2004.

[15] V. Yu. Topolov and C. R. Bowen, "Inconsistencies of the complete sets of electromechanical constants of relaxor-ferroelectric single crystals", J. App. Phys., vol. 109, March 2011. 